\title{
Percepção masculina sobre violência: um olhar dos usuários de serviços de saúde em Marília, São Paulo, Brasil
}

\author{
Male perception on violence: a view of the users of health services in Marilia, São Paulo state, Brazil \\ Percepción masculina sobre la violencia: una visión de los usuarios de servicios de salud en \\ Marília, São Paulo, Brasil
}

Carolina Barretos Fernandes. Faculdade de Medicina de Marília (FAMEMA). Marília, SP, Brasil. ca_fernandes@hotmail.com (Autora correspondente) Vinicius Spazzapan Martins. Faculdade de Medicina de Marília (FAMEMA). Marília, SP, Brasil. v_spazzapan@hotmail.com Janiele dos Santos. Faculdade de Medicina de Marília (FAMEMA). Marília, SP, Brasil. janielestos@famema.br Nathalia Mendes da Silva. Faculdade de Medicina de Marília (FAMEMA). Marília, SP, Brasil. nath_mendes@hotmail.com Juliana Carvalho Bortoleto. Secretaria Municipal de Saúde de Marília. Marília, SP, Brasil. jubortoleto@hotmail.com Sueli Moreira Pirolo. Faculdade de Medicina de Marília (FAMEMA). Marília, SP, Brasil. pirolo@famema.br

\section{Resumo}

Objetivo: este estudo buscou analisar a percepção masculina de violência a partir da sua compreensão de atos violentos. Métodos: trata-se de um estudo transversal, descritivo e exploratório no qual foram entrevistados 600 homens, entre 18 e 59 anos, pacientes ou acompanhantes de pacientes de um pronto atendimento de referência para a Estratégia Saúde da Família, de um pronto-socorro e de um ambulatório de especialidades do Departamento Regional de Saúde de Marília-SP. A coleta de dados ocorreu por meio de um questionário estruturado a respeito de identificação e de julgamento sobre atos violentos. Resultados: agressão à criança com arma de fogo, gritar e bater em criança foram caracterizados pelos homens entrevistados como atos extremamente violentos. Atos de agressão física como: socos, ameaças e tapas, foram considerados como muito violentos. Situações de média violência foram discussões entre casais, cenas de empurrão, homem segurando mulher pelos cabelos e mulher que chuta um homem. Atitudes consideradas como pouco violentas foram quando a mulher é autora de violência psicológica no casal. Conclusão: identificou-se um processo de naturalização de ações violentas pela ótica dos homens, o que requer um debate coletivo, tanto no setor de saúde quanto na sociedade em geral, para que ocorram soluções coletivas para o enfrentamento da violência enquanto problema de saúde pública.

\section{Abstract}

Objective: This study sought to analyse males' perception on violence based on their own understanding of violent acts. Methods: This is a crosssectional, descriptive, exploratory study in which 600 men, patients or companions of patients, from 18 to 59 years old, were interviewed in a reference emergency service for the Family Health Strategy and in a specialty clinic of the Regional Health Department in the municipality of Marilia, São Paulo state. Data collection occurred through a structured questionnaire regarding identification and judgment of violent acts. Results: Aggression towards a child by means of a fire gun, shouting and beating, were characterized by male respondents as extremely violent acts. Acts of physical aggression such as punches, threats and slaps were considered violent as well. Arguments between couples, scenes of pushing, man holding woman by the hair, and woman kicking men were considered acts of mild violence. Female psychological violence was regarded as little violent attitude. Conclusion: It was possible to identify a process of naturalization of violent actions from the perspective of men, which requires extensive debate both, in the health sector and in society in general, in order to achieve collective solutions to violence as a public health issue.
Palavras-chave:

Violência

Atenção Primária à Saúde

Masculino

\section{Keywords:}

Violence

Primary Health Care

Male 
Objetivo: este estudio tuvo como objetivo analizar la percepción masculina de la violencia a través de su comprensión de los actos violentos. Métodos: se trata de un estudio transversal, descriptivo y exploratorio, donde se entrevistaron a 600 hombres entre 18 y 59 años, pacientes 0 acompañantes de pacientes, en un servicio de emergencia para la Estrategia de Salud Familiar y un servicio de urgencias de un ambulatorio de especialidades del Departamento Regional de Salud de Marília-SP. Los datos se recogieron utilizando un cuestionario estructurado con respecto a la clasificación y evaluación de los actos violentos. Resultados: la agresión al niño usando arma de fuego, así como los gritos y golpes, se caracterizaron como actos de extrema violencia por los hombres encuestados. Los actos de agresión física tales como golpes, amenazas y bofetadas se consideraron demasiado violentos. Las discusiones entre parejas, empujones, hombre agarrando a la mujer por el pelo y la mujer pateando al hombre, se consideraron situaciones de violencia moderada. Las actitudes consideradas como poco violentas fueron aquellas en que la mujer practicaba la violencia psicológica en su pareja. Conclusión: se identificó un proceso de naturalización de las acciones violentas desde la perspectiva de los hombres, lo que requiere un amplio debate, tanto en el sector de la salud como en la sociedad en general, para conseguir soluciones colectivas para el enfrentamiento de la violencia como un problema de salud pública.

\section{Introdução}

O fenômeno da violência, até a década de 1960, foi historicamente conduzido pelas áreas do direito criminal e da segurança pública, não sendo aceita a premissa de que constituía um problema de saúde pública. ${ }^{1}$ Com o avanço dos estudos na área, observou-se que a violência era um disparador para processos de adoecimento, trazendo consequências como: aumento significativo na incidência de transtornos psiquiátricos, dificuldades de aprendizagem, abuso de álcool e de outras substâncias, baixa autoestima, comportamento violento, além dos altos custos envolvidos direta e indiretamente com estas situaçóes. ${ }^{2,3}$ Dessa forma, houve necessidade da incorporaçáo da violência como objeto da saúde pública a fim de prevenir, examinar e delinear planos para intervir na determinação do processo saúde-doença.

A violência está presente no cotidiano das relaçóes sociais, no entanto existem divergências conceituais entre autores que estudam essa temática. Alguns conceitos sinalizam aspectos sociais desse fenômeno ou aspectos de saúde diante dos danos provocados pelas lesóes físicas, psíquicas e morais, comprometendo a qualidade de vida das pessoas em situação de violência.

Burke ${ }^{4}$ compreende violência como um fenômeno aprendido e culturalizado, mas que passa a fazer parte dos pensamentos, mimetizando ser do biológico. Também, tem sido conceituada como abuso de poder ${ }^{5}$ que visa o outro para destruí-lo, atingindo a humanidade como um todo. ${ }^{6}$ Trata-se de um fenômeno de herança comum a todas as classes sociais, culturas e sociedades, o que fortalece a teoria de que seja intrínseco ao próprio processo civilizatório, podendo se manifestar de diversas maneiras.

Situaçôes de vulnerabilidade acerca da violência no cenário da Estratégia Saúde da Família (ESF) são vivenciadas pelos profissionais de saúde no cotidiano dos serviços, porém, na maioria das vezes, estes apenas observam o dano relatado sem poder intervir nas causas, o que os mantém distantes da realidade, impossibilitando o cuidado integral. Entre os inúmeros questionamentos que emergem dessa prática, busca-se compreender as representaçóes e os significados que definem um ato como violento.

$\mathrm{O}$ aumento nos índices de violência registrados nos últimos anos envolve o sexo masculino, ${ }^{8}$ comumente identificado como agressor, sem dimensionar o quanto este também pode ser vítima de um processo civilizatório excludente e desigual.

Para subsidiar açôes na atençâo primária, secundária e terciária à saúde; pela demora em se incorporar "o social” como variável significativa na origem das enfermidades; ${ }^{9}$ assim como para aprofundar a temática - visto que a literatura pouco aborda a respeito do entendimento de violência pelo homem, apenas traz dados sobre a repercussão de atos violentos - o objetivo do presente estudo foi analisar a percepção masculina a partir da sua compreensão de atos violentos, considerando sua singularidade.

\section{Métodos}

Trata-se de um estudo transversal, descritivo e exploratório, que foi aprovado pela Comissão de Ética em Pesquisa da Faculdade de Medicina de Marília (FAMEMA) e pela Secretaria Municipal de Saúde de Marília, protocolo 1213/10. Os sujeitos da pesquisa assinaram o termo de consentimento livre individual, atendendo aos princípios éticos e à Resolução 196/96 do Conselho Nacional de Saúde. 
A coleta de dados foi realizada durante o ano de 2011 nos seguintes serviços: pronto atendimento de referência para a ESF das zonas norte e leste do município, com média de 200 atendimentos/dia; pronto-socorro de referência para urgência do Hospital de Clínicas de Marília, com média de 400 atendimentos/dia; e ambulatório de especialidades do Departamento Regional de Saúde (DRS IX), com média de 200 atendimentos/dia e que atende a 62 municípios da região de Marília.

A amostragem não probabilística e de conveniência orientou a seleção dos entrevistados pela dinâmica de fluxo de homens presentes nos serviços, buscando-se contemplar 30\% destes no período de um mês, no momento de maior fluxo, no início das noites e nos finais de semana. Os sujeitos da pesquisa foram 600 homens, entre 18 e 59 anos, faixa esta que compreende a população mais exposta à violência e também alvo da Política Nacional de Atenção à Saúde do Homem. ${ }^{8}$ Realizou-se seleção sistemática, adotando-se critério de um para dois homens atendidos ou em acompanhamento, de acordo com a abertura das fichas de atendimento, nos momentos identificados como de maior fluxo. Os critérios de exclusão foram: pertencer ao sexo feminino, ter menos de 18 anos ou mais de 59 anos, estar sob efeito de álcool e/ou drogas ilícitas, ter prejuízo cognitivo, averiguados por avaliação clínica feita por médico de plantão nos serviços.

A coleta de dados ocorreu por meio de questionário estruturado, previamente submetido a teste piloto, com questóes a respeito de identificação, idade, estado civil, escolaridade, renda, ocupação e religiáo; e de julgamento sobre atos violentos, segundo a Organização Mundial da Saúde (OMS). ${ }^{?}$

Elaborou-se um instrumento de coleta de dados, constituído de 12 imagens que ilustravam agressóes: a) Imagem 1 - homem grita com a mulher e a puxa pelos cabelos; b) Imagem 2 - mulher chuta o homem; c) Imagem 3 - ameaçar a criança com arma de fogo; d) Imagem 4 - mulher recebe tapa no rosto; e) Imagem 5 - discussão com gritos e xingamentos; f) Imagem 6 - mulher grita com um homem; g) Imagem 7 - homem empurra o outro em situaçáo de jogo; h) Imagem 8 - discussão na presença da criança; i) Imagem 9 - homem dá soco em outro homem; j) Imagem 10 - mulher é ameaçada; k) Imagem 11 - gritar com uma criança; e l) Imagem 12 - dar palmada na criança (Anexo 1). Tais imagens foram escolhidas por expressarem atos de violência física e psicológica de gênero e contra a criança, contemplando, assim, os diferentes tipos de violência caracterizados pela OMS. ${ }^{9}$

Para cada imagem apresentada, os participantes atribuíram uma nota em uma escala de 0 a 5 (escala Likert), demonstrando suas percepçóes quanto à importância e/ou magnitude de tal ato de violência, variando de um ato aceitável culturalmente a um ato muito agressivo, sendo $0=$ Situaçáo comum, Não Violenta (NV); $1=$ Pouco Violenta (PV); $2=$ Algo Violenta (AV); 3=Violenta (V); 4= Muito Violenta (MV); e 5= Extremamente Violenta (EV). Esse instrumento foi elaborado pelos autores, tendo em vista a ausência de escalas que contemplassem essa temática.

Os entrevistadores, estudantes e profissionais da ESF, foram capacitados para a aplicação do instrumento. As entrevistas aconteceram nas salas de espera dos serviços de saúde onde os homens, atendidos ou em acompanhamento, foram convidados a participar da pesquisa. Os dados quantitativos tiveram dupla digitação e foram processados pelo programa IBM-SPSS 19 e submetidos à frequência simples.

\section{Resultados}

A população estudada foi composta por uma maioria de homens na faixa etária entre $18-30$ anos (40,7\%), em união estável (61,5\%). Com relação à escolaridade, a maior parte dos usuários apresentou ensino médio completo $(50,8 \%)$ e apenas $1,5 \%$ se declararam analfabetos. A renda familiar prevalente, em salário mínimo vigente em 2011, foi de 1-2 salários mínimos $(27,5 \%)$ e apenas $2,7 \%$ dos entrevistados afirmaram receber menos de 1 salário mínimo mensal. A religião mais citada foi o Cristianismo, por $85,3 \%$ dos entrevistados (Tabela 1).

Quando questionados sobre a magnitude de uma agressão à criança com arma de fogo, 89,7\% dos homens entrevistados a caracterizaram como algo muito violento/extremamente violento. Com relação ao ato de gritar e bater em criança, a maioria considerou ser uma atitude extremamente violenta. Todavia quando há violência entre pais do tipo discussão na presença de criança, a avaliação se mostrou como ato violento (Gráfico 1). 
Tabela 1. Perfil sociodemográfico de homens usuários dos serviços de saúde do SUS, Marília, 2011.

\begin{tabular}{|c|c|c|c|}
\hline \multicolumn{2}{|c|}{ Variáveis } & \multirow{2}{*}{$\begin{array}{c}\mathrm{n} \\
242\end{array}$} & \multirow{2}{*}{$\begin{array}{c}\% \\
40,7\end{array}$} \\
\hline Faixa etária & $18-30$ & & \\
\hline & $31-45$ & 232 & 39,0 \\
\hline & $46-59$ & 121 & 20,3 \\
\hline \multirow[t]{2}{*}{ Estado civil } & Solteiro* & 231 & 38,5 \\
\hline & Casado** & 369 & 61,5 \\
\hline \multirow[t]{4}{*}{ Ocupação } & Serviços gerais & 191 & 32,2 \\
\hline & Autônomo & 147 & 24,8 \\
\hline & Indústria & 135 & 22,8 \\
\hline & Rural e Outros ${ }^{\star \star \star}$ & 120 & 20,2 \\
\hline \multirow[t]{4}{*}{ Escolaridade } & Analfabeto & 9 & 1,5 \\
\hline & Ensino Fundamental & 206 & 34,3 \\
\hline & Ensino Médio & 305 & 50,8 \\
\hline & Ensino Superior & 80 & 13,3 \\
\hline Renda & Até 1 & 16 & 2,7 \\
\hline \multirow[t]{3}{*}{ (salário mínimo ${ }^{\star \star \star \star}$ ) } & $1-2$ & 165 & 27,5 \\
\hline & $2-3$ & 161 & 26,9 \\
\hline & $\geq 4$ & 257 & 42,9 \\
\hline \multirow[t]{3}{*}{ Religião } & Católico & 356 & 59,3 \\
\hline & Evangélico & 156 & 26 \\
\hline & Outros ${ }^{\star \star \star \star \star}$ & 88 & 14,7 \\
\hline
\end{tabular}

*Solteiros viúvos e divorciados; **Relacionamento estável, amasiados;

${ }^{\star \star \star *}$ Aposentados, desempregados e estudantes; ${ }^{* \star \star * R e n d a ~ e m ~ s a l a ́ r i o ~ m i ́ n i m o ~}$ referente a $2011 ;{ }^{* \star \star \star *}$ Outras religiões e sem religião.

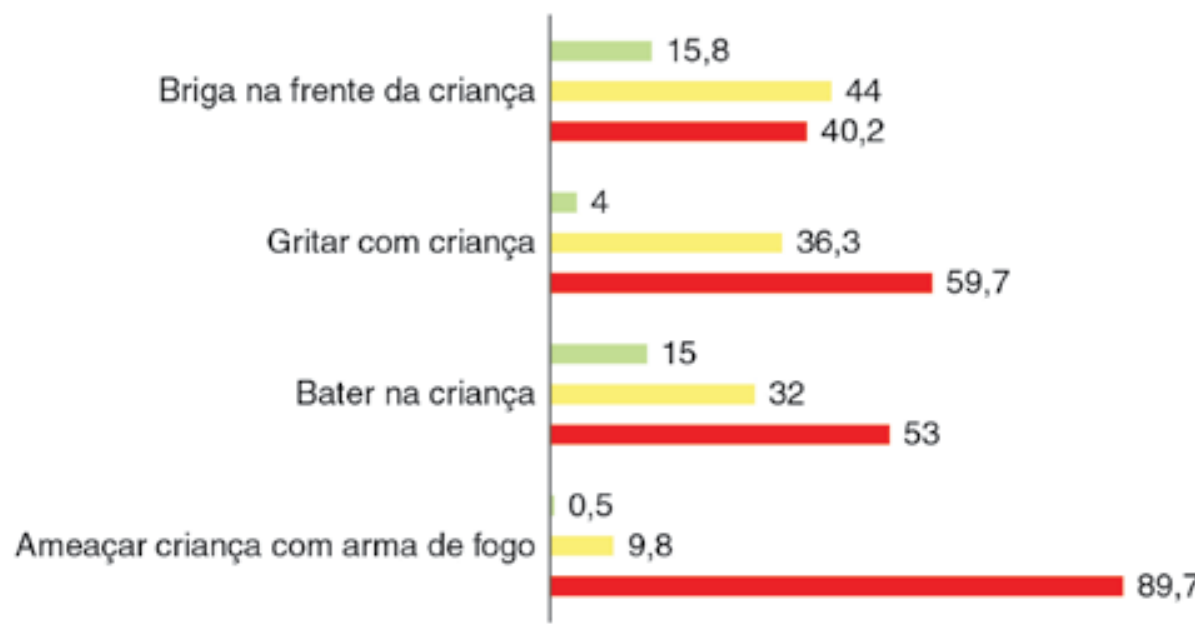

\section{= Situação comum e pouco violenta $=$ Algo violento e violento = Muito violento e extremamente violento}

Gráfico 1. Percepção acerca de atos de violência com crianças por homens usuários dos serviços de saúde do SUS, Marília, 2011.

Discussóes entre casais, com gritos e xingamentos, nas quais a mulher é a autora, os homens avaliaram como situaçóes variando entre pouco violentas a violentas. No entanto, quando ambos são autores, as cenas foram consideradas violentas, agravando-se quando existe agressão do homem contra a mulher (Gráfico 2).

Igualmente, cenas de empurrão e socos entre o gênero masculino foram vistas como um crescente de violência, sendo o empurráo considerado violento e o soco considerado extremamente violento (Gráfico 3).

Os homens na faixa etária entre 50 e 59 anos identificaram as imagens 8, 9 e 12 como sendo de extrema violência; as demais imagens foram julgadas como violentas. No entanto, os homens nas outras faixas etárias pontuaram como sendo de extrema violência as imagens $1,3,4,9,10,11$ e 12; consideraram a imagem 6 como pouco violenta; e as demais como violentas. 


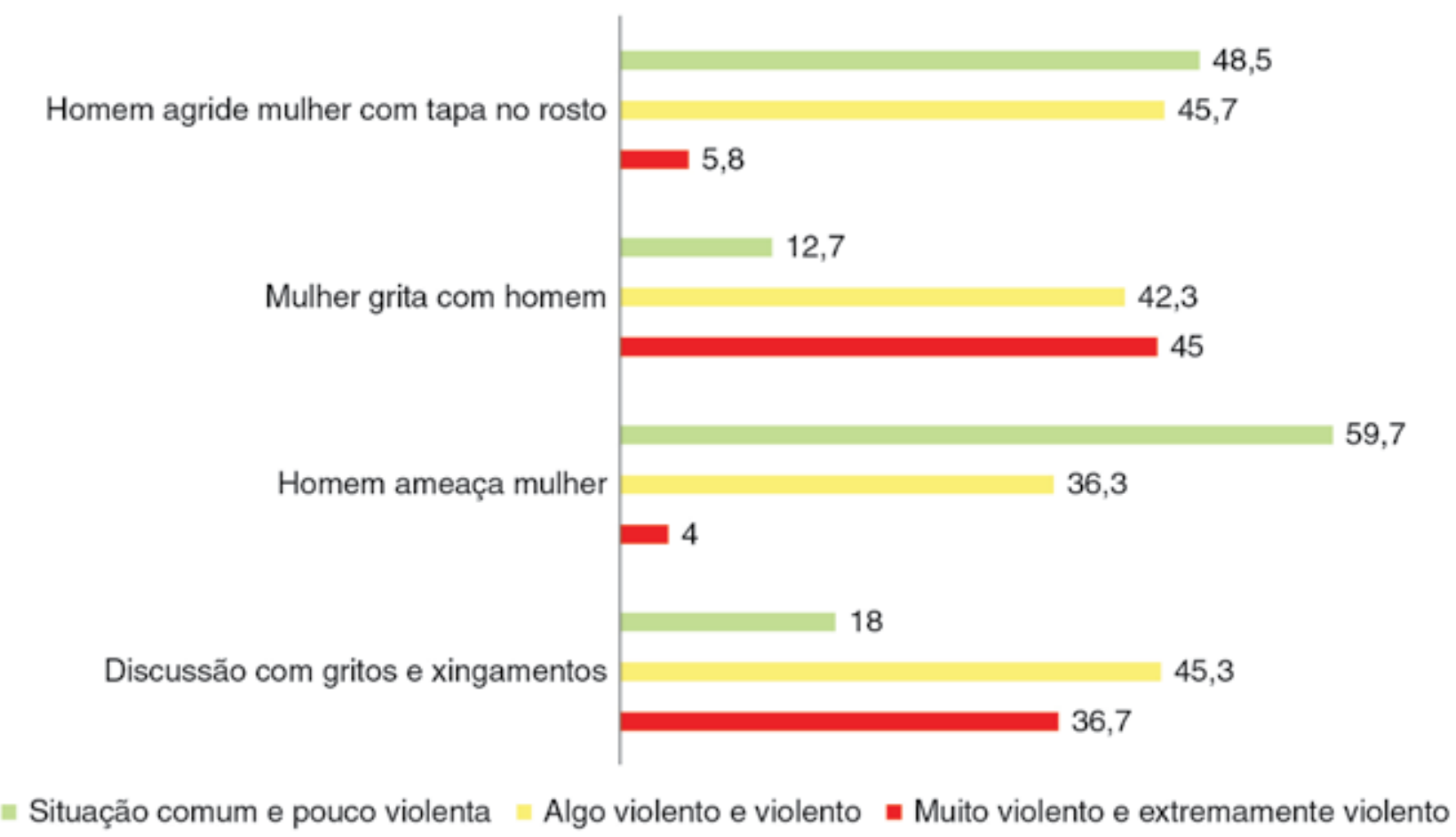

Gráfico 2. Percepção acerca de atos violentos entre gêneros por homens usuários dos serviços de saúde do SUS, Marília, 2011.

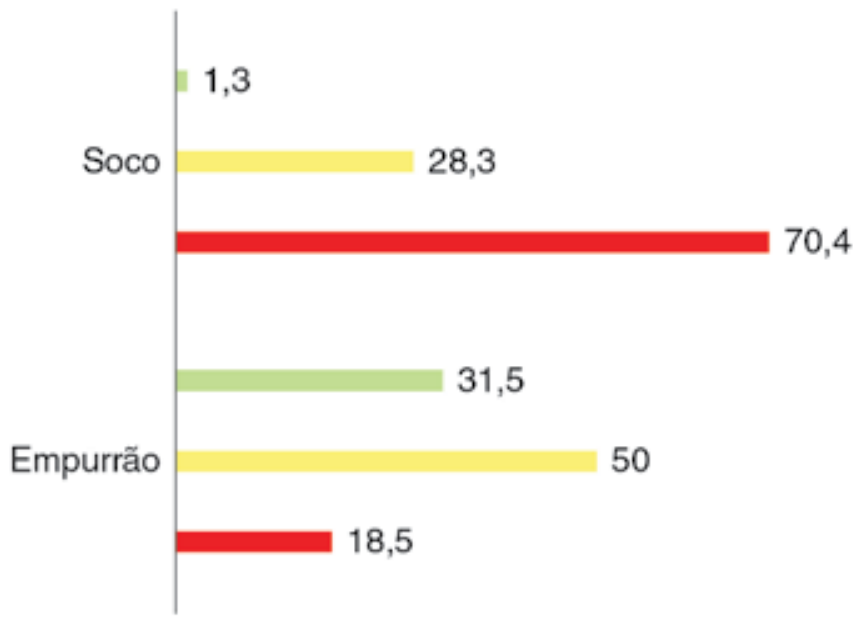

= Situação comum e pouco violenta $=$ Algo violento e violento " Muito violento e extremamente violento

Gráfico 3. Percepção acerca de atos de violência entre gênero masculino por homens usuários dos serviços de saúde do SUS, Marília, 2011.

\section{Discussão}

De acordo com a análise dos resultados, observou-se predominância do julgamento das cenas como Violentas (V) e Muito Violentas (MV) quanto à percepção dos atos de agressão. Contudo, as cenas consideradas pelos entrevistados como sendo de muita/extrema violência caracterizaram-se por situações de agressão física envolvendo crianças e adultos. Atos violentos envolviam ora agressão psicológica, ora violência física entre adultos. Por último, as cenas pouco violentas/comuns foram representadas por agressóes entre homem e mulher. 
Nas situaçôes de violência envolvendo crianças, pode-se notar que houve uma leitura pelos entrevistados de que o envolvimento de duas pessoas com desproporção física traz uma impressão impactante, traduzido como algo muito violento. Esse julgamento como inaceitável, pode ter se originado a partir de experiências vividas pelos entrevistados como vítimas do processo de violência. A literatura mostra que $20 \%$ das pessoas que relataram terem sofrido agressáo física, eram crianças e adolescentes, sendo que $80 \%$ dos agressores eram familiares e conhecidos. ${ }^{10}$ Segundo Minayo, ${ }^{11}$ em uma pesquisa com 1.328 adolescentes-escolares, $52,8 \%$ sofriam violência de um ou de ambos os pais.

De acordo com a Sociedade Brasileira de Pediatria, a violência contra crianças e adolescentes é a primeira causa de morte na faixa etária de 5 a 19 anos. ${ }^{12}$ Supóe-se que a prática da violência ainda seja uma maneira de educar as crianças, mas que pode acabar em cronicidade, como uma prática aceitável de disciplina. ${ }^{13}$ Além disso, o próprio contexto social torna a criança um alvo frágil, sendo com frequência culpabilizada por situaçôes de frustraçôes, medos, dificuldades e uso abusivo de substâncias como álcool e drogas, por parte de adultos. ${ }^{13}$

No entanto, tem-se feito um movimento no Brasil desde a década de 1980, com medidas que visem a uma conscientização das consequências trazidas pela violência impressa nos jovens. Em uma tentativa de controle de tais açóes, foi criado o Estatuto da Criança e do Adolescente ${ }^{14}$ que tornou obrigatória a notificação de situaçóes de violência por parte dos profissionais de saúde, bem como, mais recentemente, o projeto de lei $n^{\circ} 2654 / 2003^{15}$ que proíbe quaisquer formas de puniçáo corporal. A sociedade demonstrou por meio dessas mudanças que há necessidade da criação de uma nova ferramenta de educação em detrimento de transmitir aos descendentes a realidade agressiva vivida de cada um.

Por sua vez, a ameaça física por arma de fogo foi considerada de Extrema Violência (EV), fato que denota um medo enraizado pela consolidação dessa "ferramenta moderna" para a morte, já que $90 \%$ dos homicídios são cometidos por armas de fogo. ${ }^{16}$ Contudo, identificou-se que $0,5 \%$ dos entrevistados a considerou como situação comum e pouco violenta, o que pode ser indício de um processo de "naturalização" da violência devido a presença de armas de fogo nas comunidades. Esse achado requer atençáo especial e pesquisas que aprofundem essa discussão. Além dos determinantes socioculturais, parte da violência no Brasil tem sido associada também à ampla disponibilidade de armas de fogo. ${ }^{17}$ Para tanto, existem planos de intervenção por parte do governo para que se diminua o prejuízo para a sociedade, como desarmamentos voluntários, conscientizaçôes nas comunidades, apreensões de armas ilegais.

Também, entre as cenas de extrema violência, agressôes físicas entre adultos assumem um caráter inadmissível à medida que existe contato físico com o oponente e também quando há risco de desfecho trágico, como uma sequela física permanente ou até mesmo a morte. Quando há contato próximo ocorre invasão de privacidade e, dessa forma, comprometimento da segurança.

No que se refere ao grupo de atos violentos com conteúdo de violência psicológica, a posição mediana de opinião mostra que, apesar de a população masculina identificar tais atos como náo aceitáveis e de prejuízo comum, ainda assim, estes náo conseguem atribuir a mesma importância dada a algumas formas de violência física. Dessa forma, ainda há dificuldade por parte dos homens em visualizarem situaçóes psicológicas de violência que têm repercussão na formação da personalidade e, provavelmente, tudo isso reflita uma subnotificação de tais casos na rede de atenção. Por aparecer diluída a violência psicológica nem sempre é identificável, nem mesmo pela própria vítima, pelo fato de estar quase sempre atrelada a fenômenos emocionais, pela falta de referência na mídia e pela escassez de estudos sobre o tema. ${ }^{18}$

Com relação à violência entre homens e mulheres, houve divergência quanto à magnitude desse ato agressivo. A maioria dos entrevistados julgou que, quando a mulher é a agressora não é ato violento, inclusive sendo naturalizado como algo comum. Isso pode ser explicado pelo princípio de desproporção de força: a mulher, por ser fisicamente mais frágil, dificilmente apresentaria perigo físico iminente ao homem. Além disso, é consagrado culturalmente que o homem deve ser "macho", que "homem não chora", caracterizando a singularidade masculina. ${ }^{8}$

A situação muda quando o homem inicia participação na briga, situação que representa perigo de um pior desfecho, pois há a ideia ancestral de que ele deve conquistar territórios, lutar até o fim e de que ele precisa ser valente para ter status social.

Os dados levantados por este trabalho inferem o reflexo de como alguns homens enxergam a violência e, a partir desses dados, torna-se interessante ampliar a sensibilidade à violência nos espaços da Atenção Primária à Saúde (APS), buscar a aproximaçáo dos membros da comunidade, principalmente se houver auxílio de figuras proeminentes como líderes religiosos, grupos, curandeiros, entre outros, para agir nesse contexto. ${ }^{3}$ A APS oferece aos profissionais um cenário que permite trabalhar com a população a ideia de que violência é um problema de saúde, que pode ser prevenida e deve ser identificada em seus meios ocultos. A equipe de saúde tem na abordagem familiar uma ferramenta potente para ampliar os vínculos familiares e identificar situaçôes de risco. 
Ações intersetoriais poderiam auxiliar em intervençôes preventivas no enfrentamento de tais questóes. Mais do que formar profissionais que entendam os mecanismos sociais de defesa, são necessárias intervençôes universais (abordagens a grupos ou população em geral), intervençóes selecionadas (abordagens diferenciadas a pessoas sob alto risco de violência) e intervençôes indicadas (tratamento para os agressores ou para aqueles que demonstrarem comportamento violento). ${ }^{3}$

Este estudo apresenta algumas limitaçóes por utilizar um questionário não validado e entrevistar uma população de baixa escolaridade, sendo que, em alguns momentos, foi necessário auxílio por parte dos entrevistadores na interpretação das figuras. Outra limitação do estudo é que a amostra da população entrevistada difere daquela usuária dos serviços da atenção primária, tratando-se de apenas uma parcela do território da APS. Além disso, o cenário escolhido pode ter deixado os entrevistados imersos em uma variedade de sentimentos como fragilidade, impotência, desamparo, o que pode ter influenciado nas respostas.

\section{Conclusão}

O presente estudo permitiu identificar um processo de naturalização de açôes violentas pela óptica dos homens usuários dos serviços de saúde em Marília-SP ao serem aceitos atos pouco violentos como intrínsecos ao processo civilizatório, como expressão de poder e em função da carência de estratégias que cultivem a paz. A violência, por ser um problema social e de saúde pública, requer debate coletivo para formular ações que contribuam para minimizar os agravos decorrentes da agressão e da desigualdade social.

Convém destacar que a violência, em qualquer de suas manifestaçóes, causa, a longo prazo, aumento na incidência de transtornos psiquiátricos, dissociação afetiva, abuso de álcool e drogas, baixa autoestima, culpa, desenvolvimento não saudável, entre outras consequências. ${ }^{2}$ Sendo assim, pesquisar o contexto de vida das pessoas no cenário da APS, junto à intersetorialidade e à construção de novos modos de vida social, pode contribuir para entender os aspectos sociais e psicológicos que constroem a formação do ser e contribuem para a modificação desse ciclo violento.

\section{Referências}

1. Minayo MCS, Souza ER. É possível prevenir a violência? Reflexões a partir do campo da saúde pública. Ciênc Saúde Coletiva. 1999;4(1):7-23. http://dx.doi.org/10.1590/S1413-81231999000100002

2. Day VP, Telles LEB, Zoratto PH, Azambuja MRF, Machado DA, Silveira MB, et al. Violência doméstica e suas diferentes manifestações. Rev Psiquiatr Rio Gd Sul. 2003;25(1):9-21 http://dx.doi.org/10.1590/S0101-81082003000400003

3. Dahlberg LL, Krug EG. Violência: um problema global de saúde pública. Ciênc Saúde Coletiva. 2006;11:1163-1178. http://dx.doi.org/10.1590/S1413-81232006000500007

4. Burke P. Violência social e civilização. São Paulo: Braudel Papers; 1995.

5. Corsi J. Maltrato y abuso en el ámbito doméstico. Buenos Aires: Paidós; 2003.

6. Marty F. Adolescência, violência e sociedade. Agora. 2006;9(1):119-31. http://dx.doi.org/10.1590/S1516-14982006000100009

7. Gomes NP, Diniz NMF, Araujo AJS, Coelho TMF. Compreendendo a violência doméstica a partir das categorias gênero e geração. Acta Paul Enferm. 2007;20(4):504-508. http://dx.doi.org/10.1590/S0103-21002007000400020

8. Ministério da Saúde (Brasil). Política nacional de atenção integral à saúde do homem. Brasília: Ministério da Saúde; 2011.

9. World Health Organization (WHO). Putting women first: ethical and safety recommendations for research on domestic violence against women. Geneva: WHO; 2001. Document WHO/EIP/GPE/01.1 Disponível em: http://whqlibdoc.who.int/hq/2001/WHO_FCH_GWH_01.1.pdf.

10. Instituto Brasileiro de Geografia e Estatística (IBGE). Crianças e adolescentes: indicadores sociais. Rio de Janeiro: IBGE; 1989. p. 28-29.

11. Minayo MC, Assis SG. Saúde e violência na infância e na adolescência. J Pediatr. 1994;70(5):263-266. http://dx.doi.org/10.2223/JPED.685

12. Sociedade Brasileira de Pediatria. Guia de atuação frente a maus-tratos na infância e adolescência: orientação para pediatras e demais profissionais de saúde. $2^{a}$ ed. Rio de Janeiro: SBP; 2011.

13. Brito AMA, Zanetta DMT, Mendonça RC, Barison SZ, Andrade AV. Violência doméstica contra crianças e adolescentes: estudo de um programa de intervenção. Ciênc Saude Coletiva. 2005;10(1):143-149. http://dx.doi.org/10.1590/S1413-81232005000100021

14. Brasil. Lei no 8.069 de 13 de julho de 1990. Dispõe sobre o Estatuto da criança e do adolescente e da outras providencias. Diário Oficial da Republica Federativa do Brasil, Brasília; 1990 jul. 13. 
15. Brasil. Projeto de Lei $n^{\circ}$ 2654/2003. Dispõe sobre a alteração da Lei $n^{\circ}$ 8.069, de 13 de julho de 1990, o Estatuto da Criança e do Adolescente, e da Lei $n^{\circ}$ 10.406, de 10 de janeiro de 2002, o Novo Código Civil estabelecendo o direito da criança e do adolescente a não serem submetidos a qualquer forma de punição corporal, mediante a adoção de castigos moderados ou imoderados, sob a alegação de quaisquer propósitos, ainda que pedagógicos, e dá outras providências. Diário Oficial da Republica Federativa do Brasil, Brasília; 2007 jun. 26.

16. Gawryszewisk V. Homicídios no município de São Paulo: perfil e subsídios para um sistema de vigilância epidemiológica [Tese]. São Paulo: Universidade de São Paulo; 2002.

17. Reichenheim ME, Souza ER, Moraes CL, Jorge MHPM, Silva CMFP, Minayo MCS. Violência e lesões no Brasil: efeitos, avanços alcançados e desafios futuros. London: The Lancet; 2011. p. 75-89. Série Saúde no Brasil, 5.Disponível em: http://download.thelancet.com/flatcontentassets/pdfs/brazil/brazilpor5.pdf.

18. Silva LL, Coelho EBS, Caponi SNC. Violência silenciosa: violência psicológica como condição da violência física doméstica. Interface. 2007;11(21):93-103. http://dx.doi.org/10.1590/S1414-32832007000100009 
Anexo 1. Instrumento de coleta de dados.

Coloque nos parênteses o número correspondente a sua percepção de violência, sendo que: 0 - Situação comum, Não Violenta (NV);

1 - Pouco Violenta (PV); 2 - Algo Violenta (AV); 3 - Violenta (V); 4 - Muito Violenta (MV); 5 - Extremamente Violenta (EV).

\section{Imagem}

( ) Imagem 1 - Homem grita com a mulher e a puxa pelos cabelos ( ) Imagem 7 - Empurrão
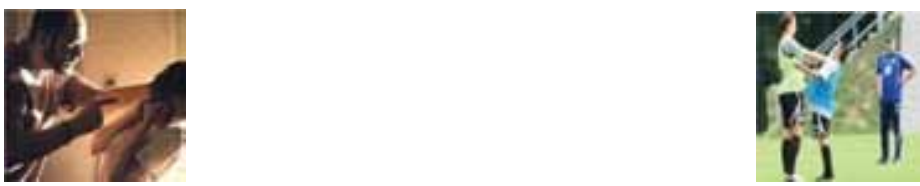

( ) Imagem 2 - Mulher chuta o homem

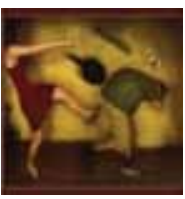

( ) Imagem 3 - Ameaçar criança com arma de fogo

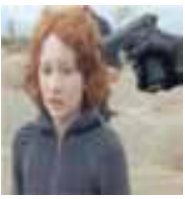

( ) Imagem 4 - Tapa no rosto

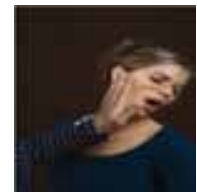

( ) Imagem 5 - Discussão com gritos e xingamentos

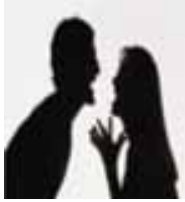

( ) Imagem 6 - Mulher grita com homem

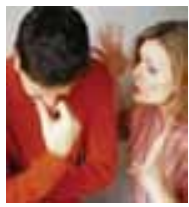

( ) Imagem 8 - Briga na frente da criança

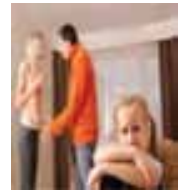

( ) Imagem $9-$ Soco

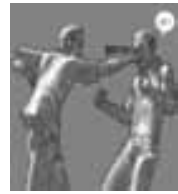

( ) Imagem 10 - Homem ameaça mulher

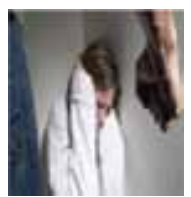

( ) Imagem 11 - Gritar com criança

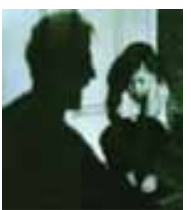

( ) Imagem 12 - Bater na criança

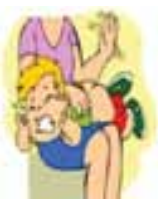

